\title{
Australian Journal of

\section{Interspecific grafting to solve the rootstock shortage in vegetative propagation of Lai-durian (Durio zibethinus $x$ kutejensis) originated from East Kalimantan}

\author{
Widi Sunaryo ${ }^{1 *}$, Hadi Pranoto ${ }^{1}$, Nurhasanah ${ }^{1}$, Rahman $^{2}$ \\ ${ }^{1}$ Department of Agroecotechnology, Faculty of Agriculture, Mulawarman University, Jl. Pasir Balengkong, Kampus \\ Gunung Kelua, Samarinda, 75123, East Kalimantan, Indonesia \\ ${ }^{2}$ UPTD, Pengawasan dan Sertifikasi Benih Tanaman Pangan dan Hortikultura, Dinas Pertanian Tanaman Pangan, \\ Propinsi Kalimantan Timur, JI. PM Noor, Samarinda, 75123, East Kalimantan, Indonesia
}

*Corresponding author: widi_sunaryo@yahoo.com

Abstract

Lai-durian (Durio zibethinus $x$ kutejensis) is a durio species derived from a natural crossing between Durio zibethinus (Durian, local name) and Durio kutejensis (Lai, local name) showing high performance of fruit quality and economic value such as golden yellow aril color, sweet and odourless taste, soft and dry texture, long shelf life (7-10 days), high edible portion, and relatively high fruit weight and yield per plant per year. The vegetative propagation of Lai-durian especially using shoot or bud grafting is facing a problem due to the low rootstock availability since Lai-durian seeds show a high percentage of abnormal/undeveloped seeds. This research was performed to evaluate the compatibility and growth performance of the interspecific grafting of two different grafting types, chip budding and cleft grafting using three different rootstock sources, $D$. zibethinus, $D$. kutejensis, and $D$. zibethinus $x$ kutejensis. Three superior national varieties of Lai-durian, i.e., Lai Kayan, Lai Mandong, and Holai Sentawar were used in this research as scion sources. The total number of 180 grafting occasions of chip budding and cleft grafting was conducted using 4-5 months-old seedling plants with $50-60 \mathrm{~cm}$ height as rootstocks. The survival rate of the successful grafting and several growth parameters, i.e., plant height, shoot and rootstock diameter, leaf number, and branch number increment were evaluated for two months. The interspecific grafting of Lai-durian on three different rootstock seedlings derived from D. zibethinus, D. kutejensis, and $D$.zibethinus $x$ kutejensis was compatible and showed a successful graft union using chip budding (94\%) or cleft grafting (60\%). The use of $D$. zibethinus and $D$. kutejensis as rootstocks could replace those of $D$. zibethinus $x$ kutejensis since there were no significant differences in the grafting compatibility and growth among the three varieties of rootstocks.

Keywords: Interspecific, grafting, Lai-durian, compatibility, rootstocks, East Kalimantan

Introduction

Durio spp. are unique endemically plants, either wildly grown or cultivated in Asian countries such as Indonesia, Thailand, Brunei, Philippines, and Malaysia. Around 30 species exist in the world (Morton, 1987) and 18 of them found in Borneo Island (Ruwaida et al., 2009; Uji, 2005). Therefore, Borneo Island is known as the center of the ecological biodiversity for Durians (Osman et al., 1995). Six of the Durian species are identified as edible species, i.e., $D$. zibethinus, D. kutejensis, D. graveolens, D. oxleyanus, $D$. dulcis, and $D$. testudinarum. Among them, D. zibethinus (Durian) is the most common edible fruit and has been entering the global market.

Durian is favoured by consumers, mostly Asian people, in terms of the diversity of flavor, aroma, color, and aesthetic aspects. The high diversity in plant morphology, fruit performance, and flavour is mostly related to the open/cross-pollinated character, as reported in $D$. zibethinus. The allogamy pollination system dominated around (30\%) compared to autogamy (11\%) (Lim and Luders, 1998). This allows $D$. zibethinus to accept various sources of pollens, even from different species/interspecific pollination. As a consequence, the progenies of this pollination system possess high genetic diversity derived from parent variation.

Lai-durian is an interspecific Durio species originated from the natural crossing between $D$. zibethinus (Durian) and $D$. kutejensis (Lai) based on the morphological observation (Sunaryo et al., 2015). Due to the high fruit performance and quality, Lai-durian had been released as an Indonesian superior variety from East Kalimantan issued by the Decree Ministry of Agriculture of the Republic of Indonesia. The high performance and economic value of Lai-durian are supported by combination properties of its parents, i.e., $D$. zibethinus (Durian) and D. kutejensis (Lai) such as golden yellow aril color, sweet, soft and dry texture, odorless, long shelf life (7-10 days), high edible portion, relatively high fruit weight and yield per plant per year (Sunaryo et al., 2015).

As an interspecific crossing-derived species, the progeny seeds resulted from the generative pollination of Lai-durian perform segregated and unstable characters. Therefore, vegetative propagation for plant material of Lai-durian production is suggested in practices, as commonly used in other fruit plants (Melnyk and Meyerowitz, 2015). Beside to 
maintain and conserve the genetic stability, vegetative propagation is objected to shortcut the harvesting time, increase the fruit quality and productivity and improve the resistance against biotic or abiotic stress (Mudge et al., 2009; Garner, 2013; Stoltz and Strang, 2018).

Among other vegetative propagation systems, budding and grafting are very common to be practiced for the Durio spp., since it offers easy application and a high percentage of successful grafting (Yuniastuti et al., 2017). In the case of $D$. zibethinus, for budding and grafting, the plant materials for bud or scion sources are usually originated from the genetically selected clones. However, for the rootstocks, randomly selected seedlings are frequently used. For the interspecific crossing-derived species like Lai-durian, the use of vegetative propagation is facing obstacles due to the limited seed sources to produce rootstocks. The limited number of seeds produced by Lai-durian is caused by the low seed quality shown by a high percentage of abnormal /undeveloped seeds (almost 50\%) (Sunaryo et al., 2015). The rest of the seeds are physiologically normal, but they are very sensitive to the pathogen attack/infection or mechanical damage since the seed coat does not cover the cotyledon completely.

The $D$. zibethinus or $D$. kutejensis produce abundant seeds during the Durian season. The seeds can be used as rootstocks sources for Lai-durian vegetative propagation using interspecific grafting, but the compatibility and the effectiveness of it is still little-known. The interspecific grafting in the same genera (heterograft) had been proven to be successfully performed at several plants such as Peach and Prunus spp. (Zarrouk et al., 2006; Gainza et al., 2015), Chestnut (Huang et al., 1994), and Chamaecyparis spp. (Holland et al., 2001). This study evaluated the compatibility and growth performance of inter and homo specific grafting between Lai-durian with different rootstocks, i.e., $D$. zibethinus, D. kutejensis, and D. zibethinus $x$ kutejensis after applying different types of grafting methods.

\section{Results}

\section{Chip budding vs. cleft grafting}

Chip budding and cleft grafting methods were successfully applied in Lai-durian, indicating that these two types of grafting can be practiced for both interspecific and intraspecific grafting in Durio spp. especially between $D$. zibethinus and $D$. kutejensis and their crossed-species. A high percentage of successful grafting was observed producing at least $60 \%$ of the grafted plants. However, chip budding system resulted in significantly higher and faster successful grafting than cleft grafting (Table 1). The percentage of successful grafting in the chip budding was $94 \%$ compared to that of $60 \%$ in the cleft grafting. In addition, a very significant faster time was needed for the chip budding (around 17 days) compared to cleft grafting (around 76 days) for the unification of the scion and rootstock tissue formation indicating the success of grafting (Table 1 ). This exhibits that the chip budding system is very effective for the mass propagation of Lai-durian varieties.

On the contrary, although the percentage and time of successful grafting of the cleft grafting were lower and slower compared to the chip budding, the grafted plants using cleft grafting grew faster and had a significantly higher number of leaves and branches (Table 1). The differences in leaf and branch number between both grafting types were suggested due to the difference of the starting points of leaf and branch number. The chip budding used single bud as scion source. On the other hand, the cleft grafting used a mature shoot containing some leaves and buds. Therefore the cleft grafting resulted in the more leaves and branches, and grew faster as well.

\section{Plant growth of Lai-durian grafting using different rootstocks}

There were no significant differences in the percentage and time of successful grafting among the three types of tested rootstocks, Lai-durian, Durian or Lai seedlings, either by chip budding or cleft grafting (Table 2). This indicates that the use of rootstocks derived from Lai-durian (intraspecific grafting/homograft) can be substituted by Durian or Lai seedlings (interspecific grafting).

However, the plant growth of Lai-durian using three Durio species as rootstock sources, representing inter and intraspecific grafting, showed that there was a significant effect of rootstocks sources to the growth and variables of grafted plant (Table 2). The use of rootstocks from three different species can produce the graft union, but it was obviously noticed that in almost all growth variables, the grafted plants using rootstocks derived from Lai-durian seedlings (D. zibethinus $x$ kutejensis ) were higher and significantly different than that of Durian (D. zibethinus) or Lai (D. kutejensis) rootstocks There was a tendency that the use of rootstocks derived from Durian (D. zibethinus) seedlings showed better growth than Lai (D. kutejensis).

Based on the observation during the first eight weeks (56 days), the plant growth pattern of Lai-durian grafted on different rootstock sources was clearly figured (Fig. 1). In general, Lai-durian grafted on the rootstock with the same genetic background (D. zibethinus $x$ kutejensis) resulted in the fastest growth such as plant height, scion/shoot diameter, leaf and branch number. This high growth rate was followed by the $D$. zibethinus and $D$. kutejensis rootstocks, respectively. On the other hand, Lai-durian grafted with $D$. kutejensis rootstock showed the slowest plant growth observed from the scion/shoot diameter, leaf, and branch number increment (Fig. 1). Interestingly, the plant growth of Lai-durian grafted on D. zibethinus rootstock showed an almost similar pattern with its homograft, $D$. zibethinus $x$ kutejensis rootstock. This indicates that the genetic similarity between scion and rootstock sources still performs the best growth of the Lai-durian both using cleft grafting or chip budding than its heterograft condition. The interspecific grafting of Lai-durian using $D$. zibethinus could be recommended as an effective alternative rootstock source because the success and growth performance of the grafting were completely similar.

\section{The scion and rootstock compatibility}

The suitability/compatibility of grafting between the scions source and rootstocks was observed using the diameter increment of upper and lower stem parts of grafting. Although this will not represent the match binding of both cambial stems completely, but it will show the suitability of growth between scions and rootstocks. Results showed that 
there were no significant differences between the scions and rootstocks growth in almost all Lai-durian varieties, especially in Holai Sentawar using cleft grafting (Table 3). Different results were shown using chip budding. There were significant stem growth differences between scions and rootstocks in the heterograft of all Lai-durian varieties with $D$. zibethinus or D. kutejensis rootstocks. However, there were no significant differences of scion and rootstock stem growth of the homograft of Lai-durian using the same genotype rootstocks in all Lai-durian varieties using the chip budding.

This indicates that there is high growth suitability between scion and rootstock stem in the cleft grafting using chip budding due to a high binding match of the cambial tissue. The cleft grafting is suitable for $D$. zibethinus, $D$. kutejensis and $D$. zibethinus $x$ kutejensis either in intraspecific or interspecific grafting. On the other hand, there was lower suitability of scion and rootstock stem growth for interspecific grafting using the rootstocks of $D$. zibethinus or $D$. kutejensis in chip budding of Lai-durian. The similar pattern was observed among the three different varieties of Lai-durian (Table 3). The chip budding resulted in high growth suitability only in the homograft of Lai-durian using a high genetic similarity of rootstock.

\section{Discussion}

Mass production of plant materials for commercial fruit cultivation, especially for the open-pollinated fruit plants, usually uses vegetative (asexual) propagation, since it maintains genetic stability and similarity of the plant materials derived from the mother plants. It will also maintain the stability of fruit performance and production (Mudge et al., 2009). The vegetative propagation has been applied to fruit plants since the ancient century (Mudge et al., 2009), especially using grafting technology. Many traditional grafting systems are known and practiced (Garner, 2013), including in edible Durio species. From the known grafting systems, the cleft grafting (shoot grafting) or chip budding (bud grafting) is the most appropriate and effective for Durio species to maintain and conserve the genetic similarity and plant production.

Lai-durian (D. zibethinus $x$ kutejensis), an indigenous Durio from East Kalimantan, is derived from the natural interspecies crossing between $D$. zibethinus and $D$. kutejensis (Sunaryo et al., 2015). It produces abnormal fruit seeds. Only about $50 \%$ of them shows good viability for production rootstocks seedling. Therefore, the grafting systems have encountered problems concerning the limited supply of seeds for rootstock sources. Practically, the use of interspecies seeds as rootstocks sources has been applied for the interspecific grafting of Lai-durian. The effectiveness of interspecific grafting (heterograft) between three superior varieties of Lai-durian as scion sources and two Durio species, i.e., D. zibethinus and $D$. kutejensis as rootstock sources were examined using two grafting systems, chip budding and cleft grafting (Table 1). The grafting using the genetically identical scion and rootstock (homograft) was also performed as a control. In general, the interspecific grafting applied in this experiment was successful expressed by the unification of the scion and rootstock tissue. The success of interspecific grafting varied from $56 \%$ to $95 \%$ using $D$. zibethinus and $61 \%$ to $90 \%$ using $D$. kutejensis as rootstocks, depending on the types of grafting applied.

The interspecific grafting is usually successful and compatible for many fruit plants (Mudge et al., 2009), except for some certain plants showing incompatibility (Gainza et al., 2015). The compatibility of the grafting does not only depend on the genetic bases of the scion and rootstock sources but, even in homograft, the graft incompatibility could happen because of the differences of the scion and rootstock age and juvenility (Wang et al., 2011). The successful grafting between different species, especially in the same genera, has also been reported in Castanea spp. (Huang et al., 1994), Prunus spp. (Gainza et al., 2015), Solanum spp. (Kawaguchi et al., 2008), Cucurbita spp. (Lee and Oda, 2003), and Citrus (Wutcher, 1979). The compatibility of the heterograft in plants is related to the genetic distance of scion and rootstock sources. The longer the genetic distance, the higher the heterograft incompatibility (Schoening and Kollmann, 1997).

The successful graft union was represented by the unification of vascular tissue and cambial layers of the scion and rootstock cut. In chip budding system, the binding of the cambial layer between the bud chip and rootstock wound is the determinant factor for the successful graft union. The binding will induce bud growth by auxin activity and accumulation. Furthermore, the graft union development also involves cell to cell communication between scion and rootstock for local auxin accumulation in triggering shoots in the scion (Yin et al., 2012). In the cleft grafting system, after the vascular tissue of the scion and the rootstock were connected, the transport of phloem and xylem will function to support plant growth. The organic compounds such as RNAs and proteins are also involved in the heterograft development and growth especially in phloem translocation (Golecki et al., 1998; Spiegelman et al., 2013).

The chip budding showed a powerful system for the interspecific Lai-durian mass propagation compared to the cleft grafting, since it could produce a higher percentage of successful grafting in a faster time, although the branch and leaf growth were significantly lower. The different results of the percentage and time for successful grafting between chip budding and cleft grafting represent the distinct characteristic of both systems concerning the effectiveness of cambial layer unification of the scion and rootstock cut. The chip budding requires a small chip containing single bud from the scion. The high possibility of the chip to bind perfectly to the rootstock wound resulted in the higher percentage and faster time of the graft union of the chip budding system, compared to cleft grafting. On the other hand, since the larger surface of the scion and rootstock cut are bound and connected in cleft grafting, the union is slower requiring longer time. It has a consequence that the cells in the surface cut cannot survive and are not viable to bind. Also, using the cleft grafting system, the mismatch shape of the scion and rootstock cut is high due to the technical aspects. The grafted plants produced by cleft grafting show a powerful growth because the scion used in the grafting had more or many bud sources compared to the chip budding containing a single bud. Buds will grow to form shoots after the scion and rootstock are successfully grafted. More buds produce more shoots represented by more branches and leaves.

In addition, the auxins acting for plant growth initiation 
Table 1. Plant growth and the successful grafting of two different grafting systems in Lai-durian after 56 days (8 weeks) of observation.

\begin{tabular}{llll}
\hline Observed Variables & Cleft Grafting & Chip Budding & t-test \\
\hline Plant height increment $(\mathrm{cm})$ & 8.82 & 10.48 & $*$ \\
Scion/shoot diameter increment $(\mathrm{cm})$ & 1.09 & 1.37 & $*$ \\
Rootstocks diameter increment $(\mathrm{cm})$ & 1.00 & 1.27 & $*$ \\
Leaf number increment & 9.22 & 4.60 & $* *$ \\
Branch number increment & 3.48 & 2.46 & $*$ \\
Percentage of the success grafting (\%) & 60.00 & 94.00 & $* *$ \\
Time for success grafting (days) & 76.56 & 17.43 & $* *$ \\
\hline Note: ${ }^{* *}=$ significant at $p \leq 0.01, *=$ significant at $p \leq 0.05$. & &
\end{tabular}
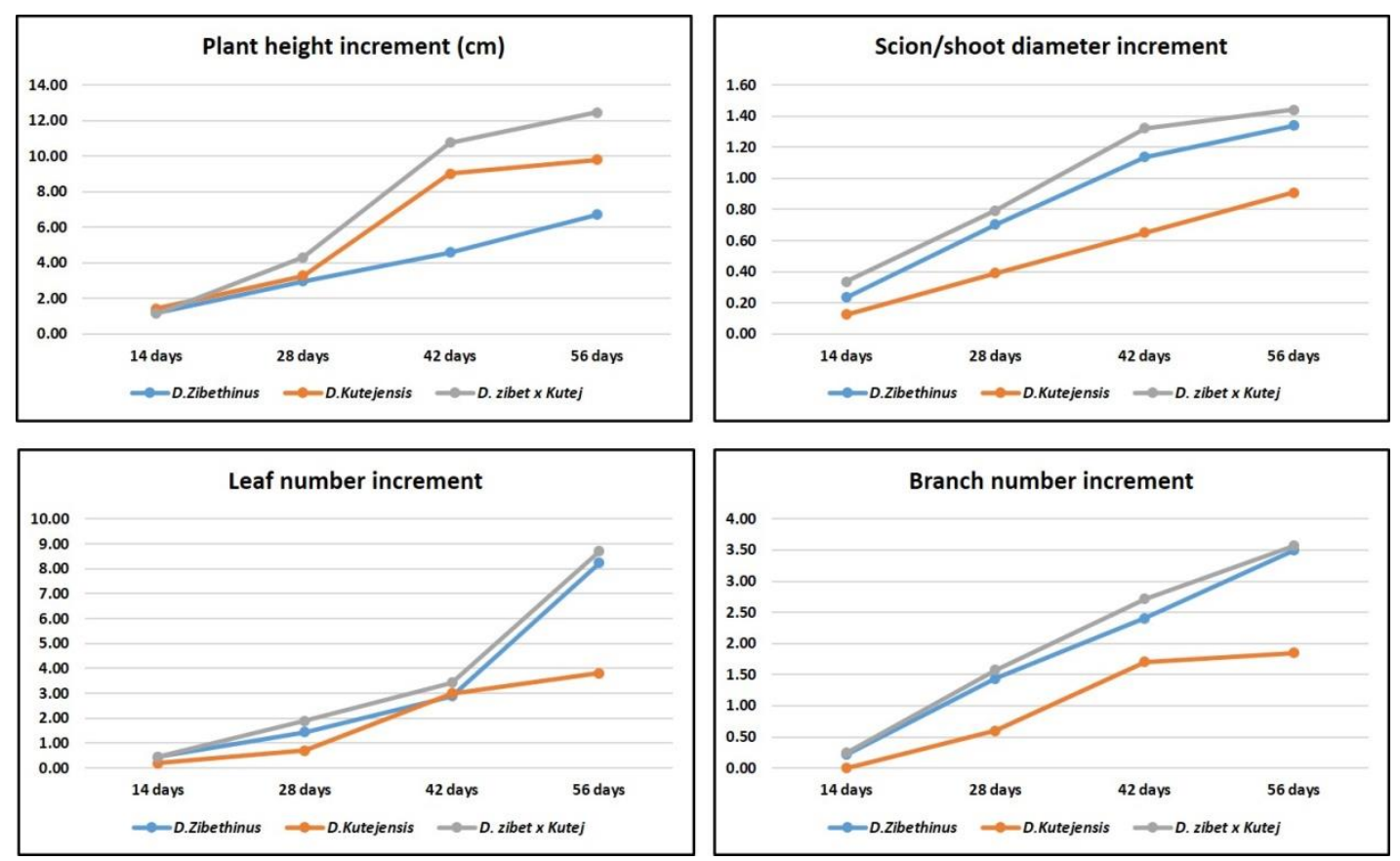

Fig 1. The growth pattern of Lai-durian grafted on three different grafting rootstocks (D. zibethinus, D. Kutejensis, and $D$. zibethinus $x$ kutejensis).

Table 2. Plant growth of Lai-durian grafted on different rootstock sources after 56 days (8 weeks) of observation.

\begin{tabular}{|c|c|c|c|c|}
\hline Growth Variables & D. zibethinus & D. kutejensis & D. zibet $x$ kutej & ANOVA \\
\hline \multicolumn{5}{|l|}{ Cleft grafting } \\
\hline Plant height increment & $7.29 \mathrm{a}$ & $8.06 \mathrm{a}$ & $11.12 \mathrm{~b}$ & $*$ \\
\hline Scion/shoot diameter increment & $1.01 \mathrm{~b}$ & $0.68 \mathrm{a}$ & $1.29 \mathrm{c}$ & $*$ \\
\hline Rootstocks diameter increment & 0.99 a & $0.74 \mathrm{a}$ & $1.29 \mathrm{~b}$ & $* *$ \\
\hline Leaf number increment & $10.41 b$ & $5.49 \mathrm{a}$ & $11.77 \mathrm{~b}$ & $* *$ \\
\hline Branch number increment & $3.74 \mathrm{~b}$ & $2.68 \mathrm{a}$ & $4.02 \mathrm{c}$ & $*$ \\
\hline Percentage of the success grafting (\%) & $56 a$ & $61 \mathrm{a}$ & $63 a$ & NS \\
\hline Time for success grafting & $76.36 \mathrm{a}$ & $77.6 \mathrm{a}$ & $75.71 \mathrm{a}$ & NS \\
\hline \multicolumn{5}{|l|}{ Chip budding } \\
\hline Plant height increment & $6.14 \mathrm{a}$ & $11.54 \mathrm{~b}$ & $13.76 \mathrm{~b}$ & $* *$ \\
\hline Scions diameter increment & $1.37 \mathrm{a}$ & $1.13 \mathrm{a}$ & $1.31 \mathrm{a}$ & NS \\
\hline Rootstock diameter increment & $1.24 \mathrm{a}$ & $1.37 \mathrm{a}$ & $1.21 \mathrm{a}$ & NS \\
\hline Leaf number increment & $6.05 b$ & $2.11 \mathrm{a}$ & $5.65 \mathrm{~b}$ & $* *$ \\
\hline Branch number increment & $3.25 b$ & $1.02 \mathrm{a}$ & $3.12 b$ & $*$ \\
\hline Percentage of the success grafting & 95 a & 90 a & $97 a$ & NS \\
\hline Time for success grafting & $17.23 \mathrm{a}$ & $18.3 \mathrm{a}$ & $16.75 \mathrm{a}$ & NS \\
\hline
\end{tabular}




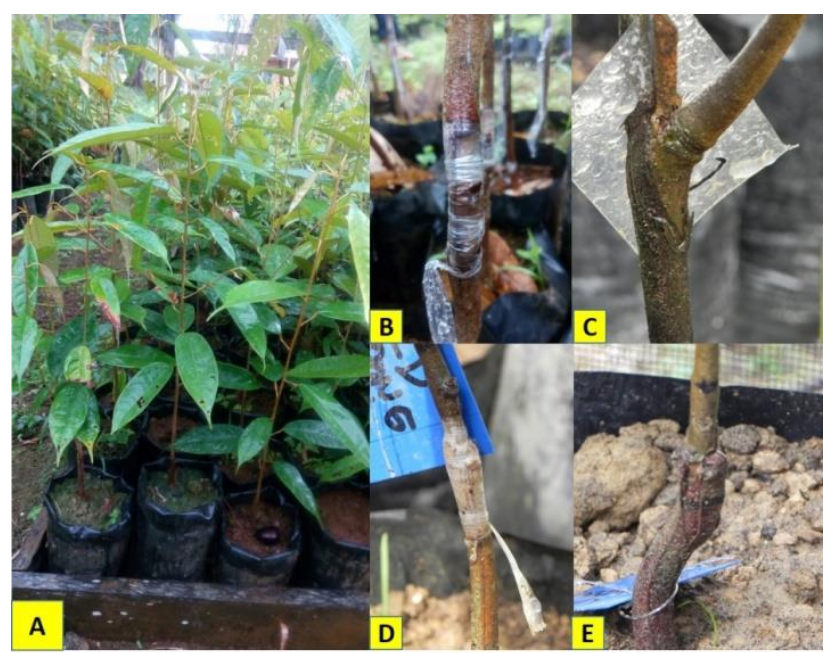

Fig 2. Chip budding and cleft grafting procedure. (A) Four-months-old-seedlings plants for Rootstocks; (B) Chip budding graft made by inserting a bud chip to a transverse cut up in a rootstock stem; (C) Graft union occurring at chip budding system; (D) Cleft graft made by inserting a scion shoot to a longitudinal cut to form a V shape; (E) Graft union occurring at cleft grafting system.

Table 3. The scion and rootstock suitability of the grafting in Durio spp. indicated by the growth of stem diamater increment.

\begin{tabular}{|c|c|c|c|c|}
\hline $\begin{array}{l}\text { Scions Sources } \\
\text { (Lai-durian Varieties) }\end{array}$ & Rootstock Sources & $\begin{array}{l}\text { Scions Diameter } \\
\text { Increment }(\mathrm{cm})\end{array}$ & $\begin{array}{l}\text { Rootstock Diameter } \\
\text { Increment }(\mathrm{cm})\end{array}$ & ANOVA \\
\hline \multicolumn{5}{|l|}{ Cleft grafting } \\
\hline \multirow[t]{3}{*}{ Lai Kayan") } & D. zibethinus & 1.04 & 0.98 & NS \\
\hline & D. kutejensis & 0.51 & 0.82 & $*$ \\
\hline & D. zibethinus $x$ kutejensis & 1.20 & 1.33 & NS \\
\hline \multirow[t]{3}{*}{ Lai Mandong } & D. zibethinus & 1.21 & 1.08 & NS \\
\hline & D. kutejensis & 0.82 & 0.72 & NS \\
\hline & D. zibethinus $x$ kutejensis & 1.33 & 1.09 & $*$ \\
\hline \multirow[t]{3}{*}{ Holai Sentawar } & D. zibethinus & 0.79 & 0.90 & NS \\
\hline & D. kutejensis & 0.75 & 0.69 & NS \\
\hline & D. zibethinus $x$ kutejensis & 1.33 & 1.45 & NS \\
\hline \multicolumn{5}{|l|}{ Chip budding } \\
\hline \multirow[t]{3}{*}{ Lai Kayan } & D. zibethinus & 1.45 & 1.11 & $* *$ \\
\hline & D. kutejensis & 1.14 & 1.52 & $* *$ \\
\hline & D. zibethinus $x$ kutejensis & 1.29 & 1.31 & NS \\
\hline \multirow[t]{3}{*}{ Lai Mandong } & D. zibethinus & 1.44 & 0.96 & $* *$ \\
\hline & D. kutejensis & 1.22 & 1.30 & $*$ \\
\hline & D. zibethinus $x$ kutejensis & 1.33 & 1.23 & NS \\
\hline \multirow[t]{3}{*}{ Holai Sentawar } & D. zibethinus & 1.23 & 1.65 & $* *$ \\
\hline & D. kutejensis & 1.02 & 1.27 & $*$ \\
\hline & D. zibethinus $x$ kutejensis & 1.31 & 1.30 & NS \\
\hline
\end{tabular}

Table 4. Scion and rootstock sources used in the experiment.

\begin{tabular}{|c|c|c|c|c|}
\hline No. & $\begin{array}{l}\text { Scion } \\
\text { (D. zibethinus } x \text { kutejensis) }\end{array}$ & $\begin{array}{l}\text { Rootstock } \\
\text { (D. zibethinus, D. kutejensis, and D. } \\
\text { zibethinus } x \text { kutejensis) }\end{array}$ & Replication & Total Experiment \\
\hline 1. & Lai Kayan") & Durian, Lai, Lai-durian & 20 times & 60 seedlings \\
\hline 2. & Lai Mandong & Durian, Lai, Lai-durian & 20 times & 60 seedlings \\
\hline 3. & Holai Sentawar & Durian, Lai, Lai-durian & 20 times & 60 seedlings \\
\hline
\end{tabular}

is produced in a shoot apical meristem (SAM), which is part of the budding system (Zhao et al., 2010). Therefore it will support the growth of new shoots in the scion.

Homograft using the identical genotype between Lai-durian scion and rootstock showed a better plant growth performance compared to the other rootstock uses, but there were no significant differences in the percentage of successful graft-union and time (Table 2 and Fig 1) with the heterograft. The better growth of the intraspecific grafting is suggested due to the absolute compatibility between scion and the rootstock to make graft union. However, the heterograft between Lai-durian (D.zibethinus $x$ kutejensis) as scion and its parents (D. zibethinus or D. kutejensis) as rootstocks was also compatible although it showed a lower 
performance of growth (Table 2). The use of D. zibethinus rootstock produced a better-grafted plant growth rather than D. kutejensis observed as superior scion/shoot diameter, leaf increment and branch increment (Fig 1). The better-grafted plant growth of $D$. zibethinus rootstocks compared to $D$. kutejensis might be caused by the different plant growth type of both species. As reported by Sunaryo et al. (2015), D. zibethinus is a fast growing and high looming plant, but $D$. kutejensis is a slow growing and umbrellashaped plant. This might contribute to the faster growing of grafted plants on $D$. zibethinus rootstocks. In addition, the other factors such as compatibility of cellular recognition, wounding response, growth regulators and compatibility toxins, and the anatomical mismatching could contribute to the grafted plant growth in tree species (Andrews and Marquez, 1993).

The compatibility of interspecific grafting of Lai-durian was performed by measuring the scion and rootstock stem growth (Table 3). No growth differences of scion and rootstock stems among the examined Lai-durian graftedplant were observed due to the close genetic similarity among the rootstock genotypes. The closer genetic relationship among varieties in the interspecific grafting caused higher compatibility of the grafted plants (Schoening and Kollmann, 1997). The same growth rate of scions and rootstocks stem diameter observed in almost all of Laidurian varieties used in this experiment showing high rate of compatibility of the grafting, although there were significant differences of such growth especially in the grafting using chip budding (Table 3 ). The differences might be caused by differences in the starting point of the stem. In chip budding, shoots could develop from a small dormant bud. In the initial phase of the plant growth, the shoot grows slowly, and then enters a rapid and maximum growth and, which consequently ends with slow growth, being called sigmoid curve growth (Soni and Soni, 2010). The rate of the growth will vary in accordance with the growth phase. In contrary, in this experiment, the scions for cleft grafting were developed into mature shoots. The buds existing along the scion have the same opportunity to grow and support the existing stem growth. This caused a balance between scion and rootstock stem growth in the cleft grafting.

\section{Materials and Methods}

\section{Scion and rootstock sources}

Interspecific grafting experiment of Lai-durian using two different systems of grafting, i.e., chip budding and cleft grafting was carried out to produce high-quality plant materials for plant cultivation. Three Indonesian superior varieties of Lai-durian (Durio zibethinus $x$ kutejensis) were used as scion and bud sources. The three varieties had been released as National (Indonesian) superior varieties, namely Holai Sentawar, Lai Mandong, and Lai Kayan. The rootstocks were derived from the $D$. zibethinus and $D$. kutejensis for interspecific/heterograft seedlings, and $D$. zibethinus $x$ kutejensis as intraspecific/homograft seedlings (control treatment). The 4-5 months-old seedlings with the $50-60 \mathrm{~cm}$ height were collected from the randomly selected cultivars. The total number of grafting experiment was 180 plants (Table 4) for each grafting methods; chip budding and cleft grafting.

Experimental design
The experiment was designed at the Completely Randomized Design (CRD) comprising of two factors, varieties of Lai-durian: Holai Sentawar, Lai Mandong, and Lai Kayan, as scion sources and the rootstock sources: $D$. zibethinus, $D$. kutejensis, and $D$. zibethinus $x$ kutejensis. All of the treatment combinations were replicated twenty times.

\section{Grafting method}

The rootstock seedlings were obtained from randomly selected seeds of three genetically chosen species, $D$. zibethinus, D. kutejensis, and D. zibethinus $x$ kutejensis. Seeds were sowed 2 to $4 \mathrm{~cm}$ deep in the horizontal position in a mixture of soil and compost medium at 1:1 ratio. All seedlings were placed under the low intensity of sunlight (about $70 \%$ ). The grafting was conducted after the seedlings reached 4-5 months-old, with an average height of $50-60 \mathrm{~cm}$ and basal stem diameter of $0.5-0.7 \mathrm{~cm}$.

Two types of grafting method were evaluated in this study, chip budding and cleft grafting. The chip budding was performed by making a transverse cut up in a rootstock at around $5-10 \mathrm{~cm}$ above the cotyledon scars using a sharp razor blade. The opposite down direction cut was made to connect the cut and formed approximately $2 \mathrm{~cm}$ long of the chip cut. The other cut was also made to take the bud from the scion with a similar size of cut in the rootstock to ensure and establish a fixed chip bud grafting. The chip budding was performed by placing the bud to the rootstock and subsequently followed by wrapping using thin and elastic plastic to tighten the binding between the bud chip and the rootstock cut (Fig. 2). Wrapping will also protect the grafting from the mechanical damage and disease attack. The wrap was removed after the grafting was success. This sign of success was the unification of the scion and rootstock tissue formation (graft union).

The cleft grafting was performed using a similar size of rootstock and scion stem diameter. A longitudinal cut to form a $V$ shape was performed in the center of rootstock stem with approximately $0.5 \mathrm{~cm}$ length for each side. The cut was applied about $2-5 \mathrm{~cm}$ above the cotyledon scars. The scions were taken from upright branches of healthy mother plants. Then, the opposite cut direction was made in the scions using a sharp blade. Both rootstocks and scions cut were combined to form a graft and to connect the cambium from both cuts. The cleft grafting was immediately wrapped tightly using thin and elastic plastic to ensure $100 \%$ match crusts (Fig. 2). The wrap was removed after the unification of the scion and rootstock tissue formation. All grafted seedlings were placed in the humid and shadow nursery for four months and maintained from the pest, diseases attack or drought stress by regular watering of the seedlings.

\section{Successful grafting, compatibility and growth observation}

The seedlings showing successful grafting were transferred to a bigger growing soil medium (10 kg polybag) containing topsoil and compost at $1: 1$ ratio. The survival rate was observed by calculating the percentage of the successful grafting compared to the total number of grafting in the same treatments. The growth parameters such as the plant height, shoot and rootstock diameter, leaf number, branch number increment were evaluated in every two weeks. After 
the plants showing successful grafting (around two months in the nursery), the grafted plants were transferred to the field and maintained by applying fertilizer application, weeding, watering, and preventing pest and disease attacks. The plant growth was evaluated for around two consecutive months during the study period.

\section{Data analysis}

Data were analyzed using Analysis of Variance (ANOVA). The differences between the mean values were tested using Honest Significant Difference (HSD) at $\alpha=5 \%$. Student's ttest was employed to compare the mean value differences between the two different grafting methods.

\section{Conclusion}

The two different types of grafting resulted in the variation in percentage and time of successful grafting. The chip budding had a higher percentage of successful grafting in a faster time compared to the cleft grafting. However, the cleft grafting had higher grafting compatibility and the more rapid growth of the grafting plants. Interspecific grafting between $D$. zibethinus $x$ kutejensis as scion/bud sources and $D$. zibethinus or $D$. kutejensis as rootstocks was compatible and successful as they created graft union. The use of $D$. zibethinus $x$ kutejensis rootstocks (homograft) resulted in the highest grafted plant growth compared to $D$. zibethinus or $D$. kutejensis rootstocks (heterograft). Nevertheless, the success and growth performance of grafting plants using $D$. zibethinus rootstock were quite similar to that of $D$. zibethinus $x$ kutejensis. Hence, the interspecific grafting of Lai-durian using $D$. zibethinus could be recommended as an effective alternative rootstock source in the mass-clonal propagation to overcome the limited number of Lai Durian seeds.

\section{Acknowledgements}

This project was financially supported by the Hibah Insentif Sistem Inovasi Nasional Nasional (INSINAS) for the year 2016-2017 research project, Ministry of Research, Technology and Higher Education, Republic of Indonesia.

\section{References}

Andrews PK, Marquez CS (1993) Graft incompatibility. Hortic Rev. 15:183-231.

Gainza F, Opazo I, Muñoz C (2015) Graft incompatibility in plants: metabolic changes during formation and establishment of the rootstock/scion union with emphasis on Prunus species. Chil J Agr Res. 75:28-34.

Garner RJ (2013) The grafter's handbook, 6th edn. Octopus Publishing Group, London.

Golecki B, Schulz A, Carstens-Bahrens U, Kollmann R (1998) Evidence for graft transmission of structural phloem proteins and their precursors in heterografts of cucurbitae. Planta. 206(4):630-640.

Holland BT, Warren SL, Ranney TG, Eaker TA (2001) Rootstock selection and graft compatibility of Chamaecyparis species. Combined proceedings international plant propagators' society, Vol. 51.
Huang H, Norton JD, Boyhan GE, Abrahams BR (1994) Graft compatibility among Chestnut (Castanea) species. Am J Soc Hortic Sci. 119(6):1127-1132.

Kawaguchi M, Taji A, Backhouse D, Oda M (2008) Anatomy and physiology of graft incompatibility in solanaceous plants. J Hortic Sci Biotech. 83:581-588.

Lee JM, Oda M (2003) Grafting of herbaceous vegetable and ornamental crops. Hortic Rev. 28:61-124.

Lim TK, Luders L (1998) Durian flowering, pollination and incompatibility studies. Ann Appl Biol. 132(1):151-165

Melnyk CW, Meyerowitz EM (2015) Plant grafting. Curr Biol. 25(5):183-188.

Morton JF (1987) Fruits of warm climates. Julia F Morton, Miami.

Mudge K, Janick J, Scofield S, Goldschmidt EE (2009) A history of grafting. Hortic Rev. 35:437-493.

Osman MB, Mohamed ZA, Idris S, Aman R (1995) Tropical fruit production and genetic resources in Southeast Asia: Identifying the priority fruit species. International Plant Genetic Resources Institute (IPGRI).

Ruwaida IP, Supriyadi, Parjanto (2009) Variability analysis of Sukun durian plant (Durio zibethinus) based on RAPD marker. Nusantara Biosci. 1(2):84-91.

Schoening U, Kollmann R (1997) Phloem translocation in regenerating in vitro heterograft of different incompatibility. J Exp Bot. 48:289-295.

Soni NK, Soni V (2010) Fundamentals of botany, Vol. 2. Tata McGraw Hill Education Private Limited, New Delhi.

Spiegelman Z, Golan G, Wolf S (2013) Don't kill the messenger: long-distance trafficking of mRNA molecules. Plant Sci. 213:1-8.

Stoltz P, Strang J (2018) Reproducing fruit trees by Graftage: budding and grafting. Nursery Crop Science, North Caroline State University.

Sunaryo W, Hendra M, Rudarmono, Suprapto H, Pratama AN, Rahman (2015) Exploration and identification of Laidurian, new highly economic potential cultivars derived from natural crossing between Durio zibethinus and Durio kutejensis from East Kalimantan. Asian J Microb Biotechnol Env Sci. 17(2):365-371.

Uji T, 2005. Keanekaragaman Jenis dan Sumber Plasma Nutfah Durio (Durio spp.) di Indonesia (in Bahasa). Buletin Plasma Nutfah 11(1):28-33.

Wang JW, Park MY, Wang L, Koo Y, Chen XY, Weigel D, Poethig RS (2011) MiRNA control of vegetative phase change in trees. Plos Genet 7(2):1-8.

Wutcher HK (1979) Citrus rootstocks. Hortic Rev. 1:237-269.

Yin H, Yan B, Sun J, Jia P, Zhang Z, Yan X, Chai J, Ren Z, Zheng G, Liu H (2012) Graft-union development: a delicate process that involves cell-cell communication between scion and rootstock for local auxin accumulation. J Exp Bot. 63(11):4219-4232.

Yuniastuti E, Annisa BA, Nandariyah, Sukaya (2017) Approach grafting of Durian seedling with variation of multiple rootstock. Bulgarian J Agr Sci. 23(2):232-237. Zarrouk O, Gogorcena Y, Moreno MA, Pinochet J (2006) Graft compatibility between cultivars and Prunus rootstocks. Hortscience. 41(6):1389-1394.

Zhao Z, Andersen SU, Ljung K, Dolezal K, Miotk A, Schultheiss SJ, Lohmann JU (2010) Hormonal control of the shoot stem-cell niche. Nature. 465:1089-1092. 